\title{
Earthen buildings in Ireland
}

\author{
Alejandro Jiménez Rios \& Dermot O’Dwyer \\ Trinity College Dublin, Dublin, Ireland
}

\begin{abstract}
Even though Irish meteorological conditions are adverse for the development of earthen constructions, earth has been used as a construction material in Ireland for more than 4000 years. The objective of this paper is to present a summarized and concise picture of the present situation of the remaining earthen buildings in the country, identify their main characteristics, the values that make such buildings important, evaluate their vulnerability as vernacular architectural style and therefore, understand and better approach any future intervention on such kinds of structures. In particular, the paper highlights the lack of a detailed description of traditional construction techniques and of recommended procedures for the conservation of existing earthen structures. The paper identifies the pertinent Irish texts and suggests how recent research on the mechanical properties of cob and state-of-the-art numerical analysis techniques and constitutive models can be used to assess the strength and stability of existing historic structures.
\end{abstract}

\section{INTRODUCTION}

Despite Ireland's wet climate, up to 255 days of rain in some parts of the country and an annual average rainfall of $1200 \mathrm{~mm}$ (MET-Eireann 2017), earthen constructions have been used in Ireland since remote times. Nevertheless, today some remaining examples can be found mainly in the east and south-eastern counties and even in other central and western parts of the Island according to Danaher (1957b) and O'Reilly (2011).

The use in Ireland of earth as a construction material is due to several economic and social factors such as the fact that appropriate soil for earthen construction can be found in most of the Irish territory and therefore can be obtained locally, avoiding material transportation expenses. Another important aspect of its wide-spread use is its ease of construction, whereas stone work requires specialized tools and skills, often dominated only by the so-called stone masters, earth is easier to work with since it is a softer material. Furthermore, the earthen construction skills were shared among most members of the rural communities. The necessary tools were very similar or the same tools as those used to work in the fields, thus being available for most of the countryside population.

\section{HISTORY}

Earth has been used in Ireland as a building material for dwellings and other facilities for more than 1000 years. Written records and archaeological evidence date it back from the period when Vikings arrived in Ireland, between the ninth and the twelfth centuries. For such constructions, earth was used as an infill material and structures were built using another construction system known as wattle and daub (Macdonald \& Doyle 1997). Gailey on the other hand, makes reference to archaeological evidence of circular dwellings built with wood or wattle from the fifth until the eighth century which would trace the use of earth for housing purposes even a couple of centuries back in the timeline (Gailey 1984). 
Focusing now in the main scope of this paper, Gailey, Macdonald and Doyle agree that cob buildings appeared in Ireland during the twelfth century with the arrival of the Anglo-Normans under the rule of King Henry. By the seventeenth century this construction system had replaced alternative practices such as wattle and daub and sod as the main technique used to build earthen dwellings. Cob buildings were widely used among the rural population, but also in towns and villages (Danaher 1957a). From the time of their introduction up until the middle of the nineteenth century, when a census revealed that half of the countryside population was living in a cob building (Macdonald \& Doyle 1997).

The history of Ireland and all its economic, social and cultural aspects cannot be understood without mentioning a catastrophic event that took place between the years of 1845 and 1852, known as the great famine, in which the population of the Island decreased by a quarter. According to some authors, (Shaffrey 1985) and (Danaher 1970), it also caused the disappearance of most of the cob houses so popular until then, due to the fact that their owners emigrated or died.

After the first half of the nineteenth century the situation for the remaining cob buildings was not very optimistic. They continued disappearing and falling into dereliction as they were regarded as being of inferior quality and had attached to themselves the horrible association of the years of scarcity. During this period housing schemes were stablished by the different County Councils aimed at providing labourers, both in towns and in the countryside, with new cottages usually built using different materials such as stone and even bricks or concrete for those constructed at the beginning of the twentieth century (Danaher 1970). The use of new materials was boosted thanks to the use of the new transportation facilities developed all around the country, starting with the first railway line between Dublin and Dun Laoghaire built in 1834 and followed by thousands of kilometres of new railways and navigable canals all across the Island (Pfeiffer 1990).

After the 1920s new purpose-built estate villages replaced lots of groups of primitive cabins around the country (most of them following the Classical style and pattern books) (Pfeiffer 1990). Moreover, Ireland went through an economic boom during the years 1960s and 1970s that brought with it a modernization period. During those years modern materials and features replaced traditional ones and sometimes earthen vernacular houses were completely rebuilt since they were considered as ancient looking, reeked of poverty, not impressive for visitors and without taking into account factors such as cosiness, easiness to heat, and the distinctive, and pleasant aesthetic character of the traditional cob buildings (Shaffrey 1985). Traditional earthen vernacular dwellings were no longer built in Ireland after the end of the nineteenth century.

\subsection{Social aspects}

The design and construction of vernacular cob buildings in Ireland were not only influenced by topographic and geographic factors but also by social and economic aspects. There have always existed two different perceptions of cob buildings as a regard of the society; a positive one and a negative one. On the one hand, the positive aspect is related to a romantic picture of the Irish countryside populated with cosy welcoming cob walled and thatched cottages of white walls and colourful roofs. Just to quote a few, in his book about his visit to Ireland, Young Hutton (1892) said:

"And if the Irish cabins continue like what I have hitherto seen, I shall not hesitate to pronounce their inhabitants as well off as most English cottagers. They are built of mud walls 18 inches or two feet thick, and well thatched, which are far warmer than the thin clay walls in England".

Shaffrey (1985) also confers cob buildings with positive aesthetic qualities such as an intimate scale of the buildings with the landscape that surrounds them, a variety of shapes and an informality of the layout. He described such buildings in the following way:

"...farm buildings and country houses fitting snugly and comfortably into the landscape as if they were also natural rather than artificial structures".

Danaher considered that vernacular dwellings had well balanced forms and pleasant proportions between walls and roof and that the lesser features such as chimneys, porches, doors and windows were well placed. Moreover he said that the texture of local materials gave them a high degree of environmental harmony (Danaher \& Irish Tourist Board 1975). Although simple and modest, vernacular houses melted perfectly with their surroundings by being built with local and ecological materials and their aesthetic characteristics are of great value in harmonizing quite nicely with the Irish countryside landscape.

On the other hand, there is the negative conception of earth buildings in which according to Shaffrey, 
they are associated with nineteenth century poverty, squalor and starvation, harsh evictions, and a substandard way of life (Shaffrey 1985). They were sometimes also associated with cottiers and landless labourers. Danaher reported (1957a):

"In the heart of the best walled towns, cities and boroughs, there stand many poor cottages of straw, chaff and clay to the eyesore of the whole town".

It is worth noting that such negative ideas about earth buildings were more related to the poorer and older cottages built using either sods or wattle and daub techniques and not necessarily to cob buildings since the use of cob system was used for both labourers and landlords to build their dwellings (Gailey 1984).

Some interesting social and folklore aspects of the Irish vernacular buildings are described by Gailey and agree with other authors as well. They point out that buildings were built by a "gathering", men, women and children participated while alternating working with singing and dancing to the rhythm of one or two fiddlers, construction techniques were inherited from generation to generation, the choice of the construction site was influenced by a folklore superstition related to fairy paths and horse skulls were placed under the hearth to improve acoustics in the building and provide good luck (Gailey 1984).

As Ireland was always a farming country, even during the Industrial Revolution period, the lifestyle and life quality as well as the characteristics and size of the buildings, were always influenced by the quality and features of the land. Furthermore, since traditional vernacular cottages were usually owner-built and owner-occupied, they present a smooth variation in shape and size as the traditional countryside occupant, farmer, artisan, carpenter, blacksmith, weaver, fisher, etc., aimed to adapt his home to his own necessities and to the requirements of his profession.

Nowadays, most of the remaining cob cottages are inhabited by "refugees from the town", people with urban rather than rural occupations migrating to the countryside to avoid the stress and the high real estate prices that entails living in a city.

\subsection{Economic factors}

Economic factors had a great influence in the development and characteristics of vernacular buildings in Ireland. Even though good construction materials were available almost everywhere around the island, only the wealthy members of higher classes could afford the payment of the professional skills of a master or the required tools needed to use more durable and stronger materials such as stone. Transportation of materials was an issue as well up until the second half of the ninetieth century, therefore most of the rural population was constrained to the use of local materials to build their dwellings.

Despite that, cob was used in some regions for both upper and lower classes as reported by (Danaher 1970). In fact, most of the remaining cob buildings still inhabited today appertained to middle or upperclass families and if they have survived up to now is because their owners could afford constant maintenance and repairs. Unfortunately, most of the earth cabins owned by the lower classes are nowadays in ruins or have completely disappeared since they were built using a lower material quality such as sods or wattle and even if they were built with cob as those of the landlords, the lack of maintenance has caused their disappearance.

Another factor that influenced the construction of new houses or the modification of existing ones was the implementation of window and hearth taxes in Ireland. Thus, houses were limited to a single hearth and some existing windows were sealed in order to reduce the economic burden that taxation would impose in poorer families (Gailey 1984).

\section{TYPOLOGY}

Classification of vernacular houses in Ireland is a complicated task since dwellings were usually ownerbuilt and configured to satisfy the necessities of their inhabitants. Therefore, small variations of size and layout exist all along the Island. Nevertheless, an overall picture of what could be defined as a traditional Irish vernacular dwelling can be stablished taking into account the definition for the typical Irish house given by Danaher (1970), since it mostly agrees with descriptions provided by other authors referenced earlier.

"We can therefore conclude that this type of house, the long, rectangular, one-storey, solid building, with its steep thatched roof and white or colour-washed walls, is the typical Irish farmhouse".

A typical plan and isometric representation of a traditional Irish earthen vernacular building is shown in (Fig. 1). Wall thickness varies from $0.40 \mathrm{~m}$ up to 0.90 $\mathrm{m}$. The height of the walls typically goes from $1.80 \mathrm{~m}$ to $3.00 \mathrm{~m}$. Wall lengths can go from $3.00 \mathrm{~m}$ up to 4.50 $\mathrm{m}$ in the wide direction of the building whereas that 
along its length buildings can reach a total distance of up to $19.00 \mathrm{~m}$. The roof may be gabled or pitched.

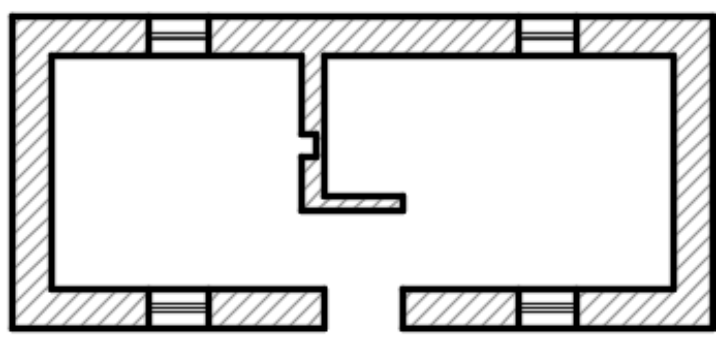

(a)

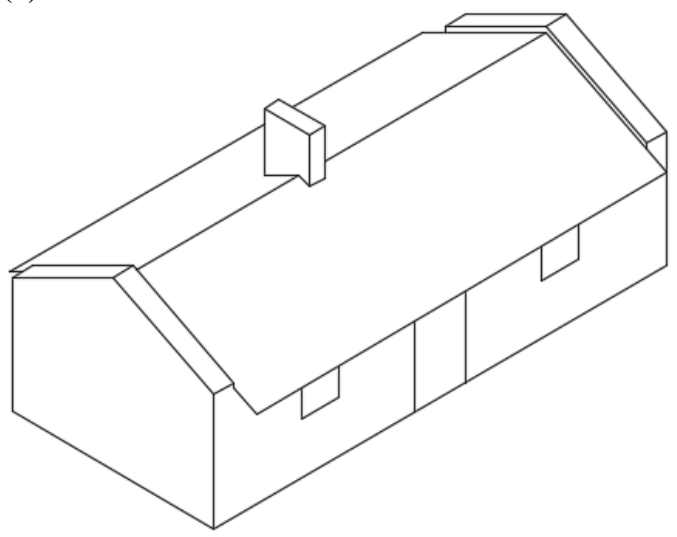

(b)

Figure 1. Traditional Irish earthen vernacular building (without scale). (a) plan view, (b) isometric view. evaluate the stabilizing effect on cob of modern materials such as gypsum, lime and cement (McPadden \& Pavia 2016). Those results are out of the scope of this paper since they do not form part of the vernacular tradition.

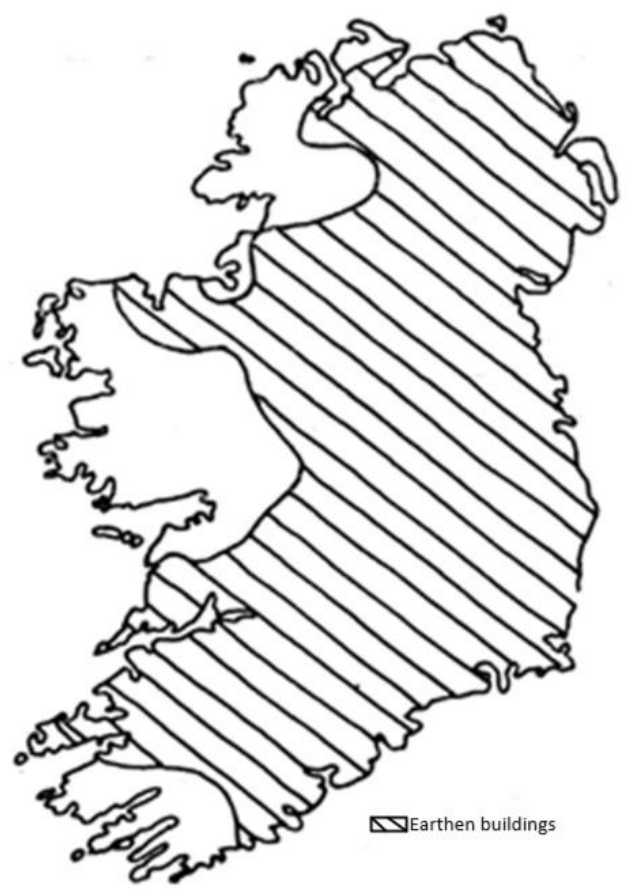

Figure 2. Earthen buildings distribution in Ireland (Danaher 1957b).

\subsection{Loam preparation}

Loam preparation was a slow and laborious process that sometimes was carried out by human or animal forces. According to (Danaher 1957b) the production of loam consisted in the steps presented in (Fig. 3). It was considered that the material was ready to be used when a sample of 45 by $30 \mathrm{~cm}$ would not bulge and the construction of the walls could start (Macdonald \& Doyle 1997).

\subsection{Dwelling construction process}

An overall picture of the construction process of historical Irish vernacular cob dwellings can be obtained from the descriptions provided by Macdonald and Doyle (1997) and Danaher (1957a). The main steps described by these authors are presented in (Fig .4).

Danaher (1957a \& 1970) places special importance to the overhang of the roof at the eaves as well as to the coats of lime wash in order to increase the durability of the cob walls. loam such as blood, urine, hair, dug, casein, milk, (Keefe 2005). Some tests have been carried out to 
Top soil is cleared.

Clay is dug up with spades, all lumps broken and stones picked out.

\begin{abstract}
Water is added and the mixture is kneaded by stirring with pitchforks and shovels, trampling with the bare feet or by driving cattle through the clay.

*Straw is added during the kneaded.
\end{abstract}

Clay mixture is left to temper for several days and turned over or re-kneaded ocasionlly.

Figure 3. Traditional process' steps to produce loam.

Keefe (1993) presented a thorough study of cob buildings in the region of Devon, England, which show several similarities with the cob dwellings of Ireland. He described similar loam preparation process and similar construction features such as the stone foundation, overhanging of the eaves and the use of lime-wash coats, all of them aiming at increasing the durability of the constructions. He reported the construction of the last major cob building in Devon to date from the year of 1912. This implies a break in the continuity of the earth building tradition in Devon of about 80 years, thus, old skills and techniques were lost and have to be relearned again which implies that all new building projects on cob tend to be of an experimental nature.

Similar phenomenon has happened in Ireland, the know-how that used to be passed from generation to generation has gotten lost due to a decrease of interest in cob buildings. This has led to an almost complete fading of this vernacular technique and nowadays efforts must be made to relearn the lost knowledge in the country.

\subsection{Mechanical behaviour}

Cob walls are considered as monolithic. Its cohesion is provided mainly by the clay cementing properties and the added organic fibres such as straw or heather (Miccoli et al. 2014). Monolithic techniques have the advantage of not presenting weakness planes such as it is in the case of modular constructions.

Efforts to understand and study earthen structures have been mainly done focusing on the traditional techniques defined as adobe and rammed earth. A long list of papers, conference proceedings and research publications can be found thanks to the work of institutions and projects such as the Getty Institute,
Terra, SAHC, NIKER, among others. Even though some of the concepts presented in this literature could be extrapolated to cob structures, the reality is that since almost no specific research has been carried out in this field, the path to understand the mechanical behaviour of cob is still not fully explored.

As said before, unfortunately no historical record exists that provides a technical description of the properties of Irish cob, neither have in-situ tests been performed to obtain such parameters. The values presented in Table 1 are taken from the literature and represent values of materials reproduced in laboratories in Germany by different authors. Regrettably that represents the closest approach that is available nowadays to understand the structural properties of cob.

Miccoli et al. (2014) determined experimentally the stress-strain curves of cob, as well as adobe and rammed earth, both under uniaxial compression and under diagonal compression. They also reported the failure mechanism and the crack patterns of the tested wallets.

From their work, they concluded that despite the low compressive strength of cob, this material presents a relatively good performance regarding the shear strength. Moreover, cob appears to be more flexible in comparison with the other two construction techniques, since it presents a relatively ductile post-peak behaviour due to the fibres added to the mixture. He also identified that a scientific study relating mechanical and mineralogical properties of these earthen building techniques is still missing (Miccoli et al. 2014).

Numerical modelling of cob has also been studied (Miccoli et al. 2017). Cob was modelled as a homogenous and continuous material using an FEM macromodelling approach. Their numerical simulations were capable of replicating the development of the shear stress-shear strain relationship but they could not replicate the crack pattern observed in the experimental tests.

Alternative numerical techniques are also available and could provide interesting results if implemented to describe the structural response of cob walls. Examples of such techniques include DEM (Cundall \& Strack 1979), DLO (Gilbert \& Smith 2007) and SPH (Lucy 1977).

\section{DECAY}

Specific decay mechanisms affecting earthen traditional vernacular buildings in Ireland are reported by 
Danaher (1957a). Due to their similarities, analogous mechanisms are reported by Keefe (1993) in his study of earthen constructions in Devon, UK (see Fig. 5).

Site marked by flat stones at the corners (fairy folklore).

A foundation of clay mortared stone is laid.

$\bullet 22.5 \mathrm{~cm}$ deep x $22.5 \mathrm{~cm}$ above ground.

-Unevenly at the top to provide "interlocking" with the clay.

Tempered clay is piled with pitchforks or shovels in layers of about $30 \mathrm{~cm}$ high over the stone foundation and well beaten down.

-Each layer of clay is covered with straw, rushes or twigs and left to set.

-When it has set hard enough, usually after one day, a new layer is added and so on until walls reache requisite height.

Clay is pared with sharp spades, hay-knifes or other suitable implements.

Creation of window and door openings.

-Use of turf sods filling.

-Use of wooden frames.

Chimney construction (140 cm wide x $90 \mathrm{~cm}$ deep, 900 $\mathrm{cm}^{2}$ opening).

-Stone (in better houses).

-Timber covered with daub and cow manure.

Construction of hearth canopies with a mixture of clay, wattle or straw rope.

Walls are whitewashed on both sides or plastered with a mixture of clay, chopped straw, animal hair, lime or cowdung.

Flat stones are placed between any timber, rafter or mantel beam and the supporting wall.

Timber roofs (usually hipped or half-hipped) thathced with straw, reeds or rushes or heather (for the poorer dwellings).

Figure 4. Cob vernacular dwelling construction process.

From all the possible factors that may affect the earthen structures in Ireland, those related to water are the most critical ones. Such factors are very common in the Island and are a result of the particular meteorological conditions highlighted in a previous chapter. The negative effects of water in the structure are commonly foster by either; neglect, inappropriate maintenance or repair, and/or to misguided alterations. Earthen walls have to be allowed to "breathe" (Keefe 1993).

Table 1. Mechanical properties of cob.

\begin{tabular}{|c|c|c|c|}
\hline Author & $\begin{array}{l}\text { (Minke } \\
2000)\end{array}$ & $\begin{array}{l}\text { (Ziegert } \\
2003)\end{array}$ & $\begin{array}{ll}\text { (Miccoli } & \text { et } \\
\text { al. 2014) } & \text { \& } \\
\text { (Miccoli } & \text { et } \\
\text { al. 2017) } & \end{array}$ \\
\hline $\begin{array}{l}\text { Compressive } \\
\text { strength } \quad \mathrm{f}_{\mathrm{c}} \\
(\mathrm{MPa})\end{array}$ & $0.5-5.0$ & $0.45-1.40$ & 1.59 \\
\hline $\begin{array}{l}\text { Tensile } \\
\text { strength } \quad \mathrm{f}_{\mathrm{t}} \\
(\mathrm{MPa})\end{array}$ & 0.0 & NR* & $(0.10-0.16) f_{c}$ \\
\hline $\begin{array}{l}\text { Tensile frac- } \\
\text { ture energy } \\
(\mathrm{N} / \mathrm{mm})\end{array}$ & $\mathrm{NR}^{*}$ & $\mathrm{NR}^{*}$ & $(0.3-0.8) \mathrm{f}_{\mathrm{t}}$ \\
\hline $\begin{array}{l}\text { Bending } \\
\text { strength } \\
(\mathrm{MPa})\end{array}$ & 0.0 & $\mathrm{NR}^{*}$ & $\mathrm{NR}^{*}$ \\
\hline $\begin{array}{l}\text { Shear } \\
\text { strength } \\
(\mathrm{MPa})\end{array}$ & $\mathrm{NR}^{*}$ & $\mathrm{NR}^{*}$ & 0.5 \\
\hline $\begin{array}{l}\text { Shear modu- } \\
\text { lus (MPa) }\end{array}$ & $\mathrm{NR}^{*}$ & $\mathrm{NR}^{*}$ & 420 \\
\hline $\begin{array}{l}\text { Modulus of } \\
\text { elasticity } \\
(\mathrm{MPa})\end{array}$ & $600-700$ & $170-335$ & 651 \\
\hline $\begin{array}{l}\text { Poisson's ra- } \\
\text { tio (-) }\end{array}$ & $\mathrm{NR}^{*}$ & $\mathrm{NR}^{*}$ & 0.15 \\
\hline $\begin{array}{l}\text { Density } \\
\left(\mathrm{kg} / \mathrm{m}^{3}\right)\end{array}$ & $1700-2200$ & $1400-1700$ & 1475 \\
\hline
\end{tabular}

The most relevant inherent defects associated with cob were identified as (Keefe 2005):

- Poorly graded soils will not provide enough compressive strength nor resistance against moisture.

- Excessive clay content can cause swelling and shrinkage (crack formation).

- Insufficient content of organic fibres will not prevent the formation of cracks in key points of the structure (corners and openings). On the other hand, excess of organic fibres can cause weak points in the structure.

- Low quality construction of early foundations and plinths.

Another major issue concerning earthen structures is the one arising from inappropriate later interventions and the materials and repair methods applied to 
carry out the works. Opening enlargements would weaken the structure, original thatch roof replacement for another material often entails a reduction in the length of overhang at the eaves thus eliminating a paramount protection feature for the earth walls against rain, the use of modern incompatible materials would undermine the local behaviour of the structure, and the application of damp proof courses or impervious coats aiming to prevent water from getting into the wall can actually have a negative consequence preventing water from getting out of the wall thus weakening it (Keefe 2005).

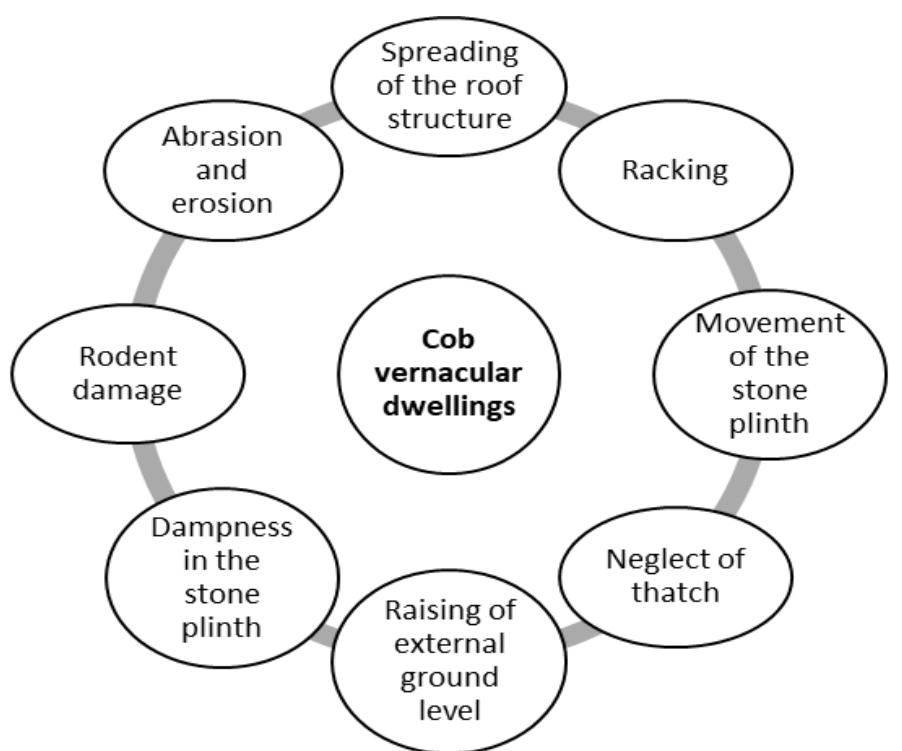

Figure 5. Causes of decay and structural failure in traditional earthen buildings.

Earth walled buildings require more frequent maintenance than those of other materials such as concrete or steel. The roof is the element that deserves more attention. Thatch, and in the case gutters, hopper heads, and downpipes also part of the drainage system, should be constantly monitored and maintained (Keefe 2005).

In his research, Miccoli et al. concluded that increased water content would not only weaken the soil but also could initiate the disintegration of the fibres thus undermining the structural response of the walls. The presence of fibres in cob is also a stimulus for insects and rodents to attack the wall and cause damage (Miccoli et al. 2014).

\section{CONSERVATION PRINCIPLES}

In the Mexico Charter (ICOMOS 1999) vernacular architecture is defined as:
"The fundamental expression of the culture of a community, of its relationship with its territory and, at the same time, the expression of the world's cultural diversity".

It was recognized that vernacular architecture is threatened worldwide by a global socio-economic transformation. It risks disappearing if it is considered to be as out of fashion, it is associated with poverty conditions, or it is regarded as of inferior quality. Those factors, together with others, such as the introduction of governmental social schemes of replacement of housing and the economic boom of the 60s70 s that brought with it the modernization of a great number of dwellings (replacing traditional and vernacular materials for modern ones), have been the cause of the almost total disappearance of such buildings in Ireland by the beginning of the $21^{\text {th }}$ century (Macdonald \& Doyle 1997), (Danaher 1970), (Pfeiffer 1990), (Shaffrey 1985).

The principles and guidance stablished in the Mexico Charter are a complement to those agreed in the Venice Charter (ICOMOS 1964) and therefore both documents should be addressed when studying or working with conservation of vernacular buildings. Generalized technical advice to select materials, inspect and assess the condition of the building, and design interventions for conservation, maintenance, repairing and/or strengthening of earthen structures is provided by several authors, see (Gailey 1984), (Minke 2000), (Keefe 2005), (Jaquin 2012) and (Historic England 2015). Interventions on traditional vernacular earthen buildings should be conservative and follow a sympathetic approach.

Furthermore, approaches to preserve vernacular buildings should focus on its conservation as a group or settlement of a specific region or community rather than to isolated cases, and must aim to its integration with the landscape (ICOMOS 1999).

In Ireland, several recommendations have been issued aiming to the preservation of such a valuable asset. For example: cabins and cottages should be restored and occupied by people serving their original aim of providing shelter and not just used as nice features to embellish the landscape (Pfeiffer 1990). Use of tourism in Ireland as means to boost conservation of vernacular dwellings, together with other measurements that may help to this purpose such as the reinforcement of the current preservation legislation, the creation of museums, like the Ulster Folk Museum in Belfast, and the reconstruction of houses belonging to historical characters (Gailey 1984). 
Irish vernacular architecture construction techniques should also be taught and researched in a modern context in the Universities of the country, otherwise they will be doomed to disappear in the near future and with them, the important knowledge and skills to maintain and preserve the existent heritage stock of the country (Danaher \& Irish Tourist Board 1975).

\section{CONCLUSIONS}

Remaining earthen buildings in Ireland are of vernacular nature and are mainly represented by the construction technique known as cob. Typical dwellings are characteristically long, rectangular in plan, one storey, solid buildings with steep thatched roofs, and lime washed walls with very specific regional variations in design.

Traditional earthen vernacular buildings in Ireland serve as historical evidence of its past, and have important socio-economic as well as intangible values attached to them. Unfortunately, little or no value is placed on vernacular architecture and there is little academic or technical research to provide assistance on this field. Of special importance is the lack of a detailed description of traditional cob mechanical properties, and the still unexplored field of numerical techniques and application of specific constitutive models to this type of material.

Nowadays, the few restoration and conservation efforts made to preserve such a valuable asset in Ireland are mainly carried out by nostalgic returning emigrants or by people that try to escape from the stress of the cities. Conservation proposals encompass the use of tourism, the reinforcement of the current preservation legislation, the creation of museums, and the reconstruction of houses belonging to historical characters.

Technical training is also of paramount importance and should be taught and researched in a modern context in the Universities of the Country, to avoid the disappearance of the Irish vernacular tradition and with it, irreplaceable knowledge and skills.

Interventions on vernacular buildings should follow a conservative and sympathetic approach in agreement with the principles and guidance stablished on international conservation charters and research results published by several authors.

\section{REFERENCES}

Cundall, P. A., and O. D. L. Strack. 1979. "A discrete numerical model for granular assemblies." Geotechnique 29 (1):47-65.

Danaher, Kevin. 1957a. "Materials and methods in Irish traditional building." Royal Society of Antiquaries of Ireland 87 (1):61-74.

Danaher, Kevin. 1957b. "Some distribution patterns in Irish folk life." Bealoideas 25:108-123.

Danaher, Kevin. 1970. The pleasant land of Ireland, A Mercier original paperback. Cork, Ire.: Mercier Press.

Danaher, Kevin, and Irish Tourist Board. 1975. Ireland's traditional houses. Dublin: Bord Filte.

Gailey, Alan. 1984. Rural houses of the north of Ireland. Edinburgh: Donald.

Gilbert, Matthew, and Colin C. Smith. 2007. "Discontinuity layout optimization: A new numerical procedure for upper bound limit analysis." IX International Conference on Computational Plasticity, Barcelona.

Historic England. 2015. Practical building conservation. Farnham: Ashgate.

Hutton, Arthur Wollaston, ed. 1892. Arthur Young's tour in Ireland (1776-1779). London: George Bell.

ICOMOS. 1964. International Charter for the Conservation and Restoration of Monuments and Sites. Venice: ICOMOS.

ICOMOS. 1999. Charter on the built vernacular heritage. Mexico: ICOMOS.

Jaquin, Paul. 2012. Earth building: history, science and conservation. Bracknell: IHS BRE Press.

Keefe, Laurence. 1993. "The cob buildings of Devon 1 \& 2." DHBT Devon.

Keefe, Laurence. 2005. Earth building: methods and materials, repair and conservation. London: Taylor \& Francis.

Lucy, L. B. 1977. "A numerical approach to the testing of the fission hypothesis." The Astronomical Journal 32 (12):1013-1024.

Macdonald, Frank, and Peigín Doyle. 1997. Ireland's earthen houses. Ireland: A. \& A. Farmar.

McPadden, James, and Sara Pavía. 2016. "An assessment of raw materials for earth construction in County Offaly, Ireland." REHABEND 2016, Burgos, Spain.

MET-Eireann. 2017. "Rainfall." MET Eireann, accessed 25/05/2017. http://www.met.ie/climate-ireland/rainfall.asp.

Miccoli, Lorenzo, Urs Müller, and Patrick Fontana. 2014. "Mechanical behaviour of earthen materials: a comparison between earth block masonry, rammed earth and cob." Construction and building materials 6:327 - 339 .

Miccoli, Lorenzo, Rui Silva, Angelo Garofano, and Daniel Oliveira. 2017. "In-plane behaviour of earthen amterials: a numerical comparison between adobe masonry, rammed earth and cob." 6th ECCOMAS Thematic Conference on Computational Methods in Structural Dynamics and Earthquake Engineering Rhodes Island, Greece.

Minke, Gernot. 2000. Earth construction handbook: the building material earth in modern architecture, International series on advances in architecture; 10. Southampton: Wit.

O'Reilly, Barry. 2011. Terra Europae Edited by Edizioni ETS.

Pfeiffer, Walter. 1990. Irish cottages. London: Weidenfeld \& Nicolson.

Shaffrey, Patrick. 1985. Irish countryside buildings: everyday architecture in the rural landscape. Dublin: The O'Brien Press.

Ziegert, C. 2003. Lehmwellerbau: Konstruktion, Schäden und Sanierung: Fraunhofer-IRB-Verlag. 